2012-10

\title{
The Effect of Genetic Background and Dose on Non-Targeted Effects of Radiation
}

\author{
Sarah Irons \\ Oxford Brookes University \\ Virginia Sierra \\ Oxford Brookes University \\ Deborah Bowler \\ Oxford Brookes University
}

See next page for additional authors

Follow this and additional works at: https://arrow.tudublin.ie/radart

Part of the Oncology Commons, and the Physics Commons

\section{Recommended Citation \\ Irons, S. et al.: The Effect of Genetic Background and Dose on Non-Targeted Effects of Radiation. International Journal of Radiation Biology, October 2012, Vol. 88 (10), p. 735-742. doi:10.3109/ 09553002.2012 .715793}

This Article is brought to you for free and open access by the Radiation and Environmental Science Centre at ARROW@TU Dublin. It has been accepted for inclusion in Articles by an authorized administrator of ARROW@TU Dublin. For more information, please contact arrow.admin@tudublin.ie, aisling.coyne@tudublin.ie, gerard.connolly@tudublin.ie.

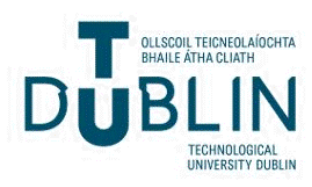




\section{Authors}

Sarah Irons, Virginia Sierra, Deborah Bowler, Kim Chapman, Stefania Mlliti, Fiona Lyng, and Munira Kadhim

This article is available at ARROW@TU Dublin: https://arrow.tudublin.ie/radart/42 


\section{The effect of genetic background and dose on non-targeted effects of radiation}

Sarah L. Irons ${ }^{1}$, Virginia Serra ${ }^{1}$, Deborah Bowler ${ }^{1}$, Kim Chapman ${ }^{1}$, Stefania Militi ${ }^{2}$, Fiona Lyng ${ }^{3}$, Munira Kadhim $^{1}$

${ }^{1}$ Department of Biological and Medical Sciences, Faculty of Health and Life Sciences, Oxford Brookes University, Gipsy Lane, Headington, Oxford, OX3 OBP, UK.

2 MRC Harwell, Radiation and Genome Stability Unit, Harwell Science and Innovation Campus, Oxfordshire, OX11 ORD, UK.

${ }^{3}$ Radiation and Environmental Science Centre, Focas Institute, Dublin Institute of Technology, Kevin St, Dublin 8, Ireland.

Correspondence: Professor Munira Kadhim, Department of Biological and Medical Sciences, Faculty of Health and Life Sciences, Oxford Brookes University, Gipsy Lane, Headington, Oxford, OX3 OBP, UK. Tel: +44 (0)1865 483954. Fax: +44 (0)1865 483242. E-mail: mkadhim@brookes.ac.uk

Running title: Differential signalling in radiation-induced genomic instability

Keywords: low dose effects, radiation, non-targeted effects, genomic instability 


\section{Abstract}

Purpose: This work investigates the hypothesis that genetic background plays a significant role in the signalling mechanisms underlying induction and perpetuation of genomic instability following radiation exposure.

Materials and methods: Bone marrow from two strains of mice (CBA and C57), were exposed to a range of X-ray doses (0, 0.01, 0.1, 1 and 3 Gy). Different cellular signalling endpoints: apoptosis, cytokine levels and calcium flux, were evaluated at $2 \mathrm{~h}, 24 \mathrm{~h}$ and $7 \mathrm{~d}$ post-irradiation to evaluate immediate and delayed effects.

Results: In CBA (radio-sensitive) elevated apoptosis levels were observed at 24h post X-irradiation, transforming growth factor- $\beta$ (TGF- $\beta$ ) levels were additionally shown to increase with time and dose. C57 showed a higher background level of apoptosis compared to CBA, which was sustained 7 days after radiation exposure. Levels of tumor necrosis factor- $\alpha$ (TNF- $\alpha$ ) were also increased at day 7 for higher X-ray doses. TGF- $\beta$ levels were higher in CBA, whilst C57 exhibited a greater TNF- $\alpha$ response. Calcium flux was induced in reporter cells on exposure to conditioned media from both strains.

Conclusions: These results show genetic and dose specific differences in radiation-induced signalling in the initiation and perpetuation of the instability process, which have potential implications on evaluation of non-targeted effects in radiation risk assessment. 


\section{Introduction}

In the classical model of ionizing radiation, damage is induced directly through energy deposition causing lesions within hit cells. Whilst this model holds true for some radiation effects, it fails to encompass the range of damage observed spatially and temporally separate from a direct radiation insult. These include genomic instability (GI), where increased rates of aberrations are observed many generations after radiation exposure (Kadhim et al. 1992, Ponnaiya et al. 1997), and bystander effects (BE) where non-hit cells exhibit damage when allowed to communicate with irradiated cells (Nagasawa and Little 1999). The phenomena of $\mathrm{Gl}$ and BE are termed 'non-targeted effects of radiation' and have the potential to elicit an adaptive response (Morgan 2003 a and b). The manifestation of non-targeted effects of radiation have been described widely at the phenotypic level, however the mechanisms that underlie these processes are not fully defined at present. It is clear that certain factors have a strong influence in the appearance and manifestation of nontargeted effects, these include: genetic predisposition (Kadhim et al. 1994, Watson et al. 1997, Watson et al. 2001) and radiation type and dose (Kadhim et al. 2006, Esposito et al. 2006). Cytokines, $\mathrm{Ca}^{2+}$ fluxes and reactive oxygen (ROS) and nitric oxide species (NO) have previously been shown to be involved in responses to radiation in a range of cell systems (Dieriks et al. 2010, Ivanov et al. 2010, Facoetti et al. 2006) and in how genomic instability is perpetuated through multiple cell divisions (Averbeck 2010), but definitive links remain elusive.

Cytokines are involved in a range of cellular regulating pathways, and it is known that tumor necrosis factor- $\alpha$ (TNF- $\alpha$ ) and transforming growth factor- $\beta$ (TGF- $\beta$ ) levels are reported to change in response to irradiation (Facoetti et al. 2006, Lorimore et al. 2008, Burr et al. 2010). TNF- $\alpha$ is involved in inflammatory responses, activating nuclear factor kappa-light-chain-enhancer of activated B cells (NFkB), mitogen-activated protein kinases (MAPK) pathways and apoptotic pathways. In the case of ionizing radiation, DNA damage is proposed to initiate a cytoplasmic signalling cascade leading to NFKB activation through activation of inhibitor of kappa B kinase (IKK). The signalling molecules upstream of IKK have not been elucidated (Liu 2005) It is of note that some cell signalling molecules of the TNF pathway: receptor interacting protein (RIP), TNF receptor-associated factor 2 (TRAF2) and cJun N-terminal kinases (JNK), are also key regulators of ROS/oxidative induced cell death (Shen et al. 2004). TGF- $\beta$ has anti-proliferative action via the SMAD (a protein family sharing homology with drosophila 'mothers against decapentaplegic' (Mad) and the $C$. elegans Sma gene products) apoptotic 
pathway, it is also involved in cell cycle regulation (G1 arrest), and plays a role in early stages on oncogenesis. Mutations/inactivation of the TGF-R/SMAD pathway are linked to several forms of cancer (Shi and Massagué 2003). TGF- $\beta$ affects hundreds of genes in various combinations, leading to a range of final effects, which are influenced by cell type and conditions at activation (Shi and Massagué 2003). In recent publications both changes in TNF- $\alpha$ and TGF- $\beta$ levels have been observed after exposure to low dose radiation in different model systems. Production of a range of cytokines has been observed in response to whole body irradiation of BALB/c with low doses of X-rays (Cheda et al. 2008), these included TNF-a, interleukins (IL) IL-1B and IL-12. TGF- $\beta$ and reactive nitrogen species have been associated with bystander signalling following 'low dose' high linear energy transfer (LET; alpha particle) exposure (Han et al. 2010) in CHO cells. Whilst there is a clear role for cytokines in radiation responses, evaluation of the role of such signalling molecules in relation to nontargeted radiation effects has not been conducted.

Intracellular calcium signalling is involved in the control of cell functions including secretion, enzyme activation, cell cycle regulation, influence cell proliferation and differentiation and also modulates apoptosis (Orrenius et al. 2003). Calcium fluxes have previously been shown to be induced in HPV-G reporter cells exposed to irradiated cell conditioned media (ICCM) (Lyng et al. 2011, Shao et al. 2006, Mothersill et al. 2006), implicating $\mathrm{Ca}^{2+}$ signalling in the bystander signalling and/or response. This calcium response has been associated with a subsequent loss of mitochondrial membrane potential and ultimately increased apoptosis rates (Lyng et al. 2002, Maguire et al. 2005). Apoptosis is a form of programmed cell death, initiated through several distinct pathways. The role of apoptosis in radiation responses is linked to DNA damage and signalling events, providing a balance between DNA damage repair and removal of irreparable damaged cells (Takahashi et al. 2010). We and others have shown a genetic dependence in apoptotic response following both in vitro and in vivo exposure in mice (Gridley et al. 2011, Mothersill et al. 2005, Coates et al. 2008a).

The aim of this study was to investigate signalling mechanisms involved in initiation and ongoing radiation-induced genomic instability events, with particular attention to genetic predisposition and radiation dose as factors influencing signalling and instability induction. In order to address the role of genetics in this process, bone marrow from two strains of mice known to exhibit different radio- 
sensitivities were used. Analysis of apoptosis levels, selected cytokine levels and calcium flux initiation were used to study strain specific signalling at several time points post low LET X-ray exposure. 


\section{Materials and methods}

\section{Bone marrow harvest}

Femoral bone marrow cells from two in-bred mouse strains, $\mathrm{CBA} / \mathrm{CaH}$ and $\mathrm{C} 57 \mathrm{BL} / 6 \mathrm{~J}$, bred in the Mary Lyon Centre, at the MRC Harwell, Harwell Science and Innovation Campus, Oxfordshire, UK, were used. All the mice were kept under the guidance issued by the Home Office code of practice and the Medical Research Council (MRC). All work had been ethically approved locally by the MRC, which was reviewed annually by their review committee. Briefly, 10-12 week old male mice were used to prepare a single cell suspension using $10 \%$ horse sera (Harlan Sera-Lab, Belton, UK).

\section{X-ray irradiation}

Cells were exposed in $30 \mathrm{ml}$ universal containers (Sterilin, Newport, UK) to 0, 0.01, 0.1, 1 and 3 Gy Xrays $(250 \mathrm{keV})$ at a cell concentration of $5 \times 10^{6}$ cells $/ \mathrm{ml}(5 \mathrm{ml}$ per universal).

\section{Bone marrow and reporter cell culture}

Conditioned media required for optimal growth of bone marrow was produced as follows: Rat AF119T cells or L929 mouse cells (both cell lines kind gifts from Dr Barrie Lambert, St Bartholomew's Hospital) are grown in complete media comprising of minimum essential media- $\alpha$ (MEM $\alpha$ ) media, $1 \%$ L-Glutamine (Invitrogen, Paisley, UK), 10\% Foetal bovine sera and 1\% Penicillin-Streptomycin solution (Sigma, Gillingham, UK) in a fully humidified incubator at $37^{\circ} \mathrm{C}, 5 \% \mathrm{CO}_{2}$. When the cells reached 9095\% confluence the media was carefully removed from the culture flasks, aliquot into sterile $50 \mathrm{ml}$ tubes and centrifuged at room temperature for 10 minutes at $1200 \mathrm{rpm}$. The resulting supernatant is the 'conditioned media', this was collected in sterile Duran bottles and stored at $-20^{\circ} \mathrm{C}$ until required.

For each experimental group, bone marrow cells were pooled from the corresponding universals and were then cultured in $75 \mathrm{~cm}^{2}$ cell suspension culture flasks $\left(2.5 \times 10^{7}\right.$ cells/flask), containing MEM $\alpha$ media supplemented with $25 \%$ horse sera (Harlan Sera-Lab, Belton, UK), sources of pre-tested in-house 'conditioned media' (25\% AF1-19T and 20\% L929), 1\% penicillin-streptomycin and 1\% 200mM L-glutamine (suppliers as above).

Flasks were incubated at $37^{\circ} \mathrm{C}, 5 \% \mathrm{CO}_{2}$ before harvesting of cells (for apoptosis studies) and collection of irradiated cell conditioned media (for cytokine and calcium flux analysis) at several time-points: $2 \mathrm{~h}$ 
(0 population doublings (PD); immediate), 24h (1 PD; early) and 7 days (13-15 PD; delayed). For calcium flux imaging assays, L929 murine fibroblast cells were cultured in the same type of media as the bone marrow cells. The L929 cells are mouse connective tissue fibroblasts established from the normal subcutaneous areolar and adipose tissue of a male C3H/An mouse.

\section{Apoptotic analysis using flow cytometry with Annexin V labelling}

Where possible $5 \times 10^{5}$ cells were used for each group, reagent volumes were adjusted accordingly if a lower number of cells were available. Samples were centrifuged at $67 \mathrm{~g}$ for $7 \mathrm{~min}$ at room temp, and supernatant retained for enzyme-linked immunosorbent assay (ELISA) analysis. Subsequent steps were performed under low light conditions: For cell suspensions of $5 \times 10^{5}$, pellets were re-suspended in $400 \mu \mathrm{l}$ Buffer (1x), and samples transferred to fluorescence activated cell sorter (FACS) tubes. 12.5 $\mu \mathrm{l}$ annexin V (BD Pharmingen, Oxford, UK) was added and gently mixed. Samples were incubated in the dark, at room temp for $15 \mathrm{~min}$. $5 \mu \mathrm{l}$ propidium iodide $(50 \mu \mathrm{g} / \mathrm{ml})$ was added, and samples were immediately analysed by flow cytometry. Due to limited samples the apoptosis was only performed once.

\section{Cytokine analysis by ELISA}

For each group, supernatants from the Annexin $\mathrm{V}$ and initial Western centrifugations were combined in Amicon ${ }^{\circledR}$ Ultra-15 filter columns (Millipore, Watford, UK) in order to separate out proteins greater than $5 \mathrm{kDa}$ in molecular weight. The columns were centrifuged at $4000 \mathrm{~g}$ for $45 \mathrm{~min}$ at room temperature. Cytokine analysis of the supernatants was performed using Quantikine kits for detection of total TGF- $\beta$ (latent + active forms of TGF- $\beta$ ) and active TGF- $\beta 1$, and TNF- $\alpha$ (R\&D Systems, MN, USA). Cell supernatant samples were plated onto the appropriate ELISA plate with relative controls and standards as per manufacturer's instructions.

\section{Ratiometric measurement of calcium}

A key requirement for reporter cells is that they be receptive to bystander signals, however not all cell lines possess this prerequisite. The mouse fibroblast L929 cells used in this study were exposed to media from irradiated cells and shown to undergo a clear bystander response (data not shown) and as such were considered a suitable candidate for a murine reporter cell line. 
For imaging $\mathrm{Ca}^{2+}$ flux, $\mathrm{L} 929$ cells were seeded $24 \mathrm{~h}$ prior to imaging; at a density of 200,000 per 35mm MatTek glass bottom culture dish (MatTek Corporation, MA, USA) in 2ml media, the cells grew to 50$60 \%$ confluence at the time of use. Ratiometric imaging was performed as previously described (Lyng et al. 2006). Briefly, cells were loaded with Fluo3/Fura Red and imaging performed by confocal laser scanning microscopy. Continuous image acquisition was used to take baseline measurements and then monitor the effects of addition to the dish of either control or irradiated cell conditioned media which had been taken from the bone marrow cultures at time points of $2 \mathrm{~h}, 24 \mathrm{~h}$ and 7 days post irradiation.

\section{Statistical analysis}

One-way analysis of variance (ANOVA) with Bonferroni post-test was performed on cytokine data using GraphPad InStat 3 (GraphPad Software, CA, USA). Two proportions test (Minitab 15, PA, USA) was used to calculate $p$ values for the apoptosis data.

\section{Results}

Levels of TGF- $\beta$ and TNF- $\alpha$ show strain specific differences

Levels of TGF- $\beta$ and TNF- $\alpha$ were measured in ICCM (irradiated conditioned cell medium) from 0, 0.01 , 0.1, 1 and 3 Gy irradiated CBA and C57 haemopoietic cells at 2h, 24h and 7 days following X-ray exposure. For CBA there was a small (but not statistically significant) increase in TGF- $\beta$ levels (Fig 1.A) after $2 \mathrm{~h}$ for the 1 and $3 G y$ samples. Levels of TGF- $\beta$ declined at $24 \mathrm{~h}$ but were elevated above control levels in all irradiated groups at day 7, mainly following a dose-dependent increase (with the exception of 0.1Gy). Levels of TGF- $\beta$ in all C57 samples were far lower than those for CBA, showing no increase above control levels for all time points (Fig 1C). There were no detectable levels of TNF- $\alpha$ at the $2 \mathrm{~h}$ time point for either strain (Fig 1B and 1.D). In CBA there was detectable TNF- $\alpha$ at $24 \mathrm{~h}$ in the 0.1 - 3 Gy groups, following a dose-increase trend. At 7 days post-irradiation TNF- $\alpha$ was barely detectable in the CBA supernatant samples. In contrast, at the $24 \mathrm{~h}$ time point C57 showed a marked decrease in TNF- $\alpha$ levels in all irradiated groups when compared to the sham irradiated control (Fig 1.D). Whilst on day 7, levels of C57 TNF- $\alpha$ were highest, with the 1 and 3 Gy samples showing an increase above control, however, levels in the $0.01 \mathrm{~Gy}$ and $0.1 \mathrm{~Gy}$ C57 7d samples fell below the sham control level. The $0.01 \mathrm{~Gy}$ sample had levels approximately half to that of the concentration of the corresponding control group. Overall, there were marked strain specific differences in the selected 
cytokines observed, with TGF- $\beta$ levels in CBA samples higher than those for C57 samples at all time points, whilst C57 samples showed a greater TNF- $\alpha$ response at day 7 , though CBA did show a small peak of TNF- $\alpha$ at $24 \mathrm{~h}$. Due to variability in concentration measurements differences in the levels of TGF- $\beta$ and TNF- $\alpha$ observed changes did not reach statistical significance.

Initiation of calcium flux in 2929 reporter cells

Calcium flux was induced in the $L 929$ reporter cells on exposure to irradiated conditioned media from both CBA and C57. The $2 \mathrm{~h}$ ICCM CBA samples all induced calcium fluxes of similar magnitude and with following similar temporal dynamics (Fig 2.A). The $2 \mathrm{~h} 0.01$ - 1 Gy C57 samples all initiated fluxes; however the 3 Gy sample exhibited no clear calcium flux activity (Fig 2.B). The lower dose 24 h post Xirradiation CBA media, showed a higher magnitude of flux compared to the 3 Gy samples (Fig 2.C). Whereas the $24 \mathrm{~h}$ ICCM C57 samples all initiated calcium fluxes of similar type (Fig 2.D). The 0.01 and 1 Gy CBA 7d samples gave rise to a sustained calcium flux, not observed with the other media samples (Fig 2.E). The $3 \mathrm{~Gy}$ media gave rise to a small gradual increase in calcium levels over the duration of monitoring and the $0.1 \mathrm{~Gy}$ sample initiated a flux similar in form to the $2 \mathrm{~h}$ and $24 \mathrm{~h}$ time points. At the $7 \mathrm{~d}$ time point for $\mathrm{C} 57$ samples, $\mathrm{Ca}^{2+}$ flux was initiated by all the ICCM samples (Fig 2.F) with the lower dose $(0.01$ and $0.1 \mathrm{~Gy})$ media showing a greater magnitude of flux than the higher dose samples ( 1 and $3 \mathrm{~Gy}$ ). Sham irradiated control media for each strain and time point showed no initiation of calcium flux (Fig 2.G and $\mathrm{H}$ ).

\section{Apoptosis levels at different time points post X-irradiation}

Levels of apoptosis showed deviation from control at the higher radiation doses ( $p=0.000$ CBA 3 Gy; C57 $1 \mathrm{~Gy}$ and $3 \mathrm{~Gy}$ ) for both strains at the $2 \mathrm{~h}$ time point (Figure 3), notably C57 showed a slightly higher background level of apoptotic cells compared to CBA (C57 mean $=10.7 \%$ apoptotic cells; CBA mean $=8.7 \%$ apoptotic cells). In CBA significantly elevated apoptosis levels were observed at 24h post irradiation (Fig 3.A), at 0.01, 0.1, 1 and 3 Gy with the higher doses showing apoptosis levels around $15 \%$ ( $p=0.000$ for all samples compared to control). The C57 samples (Fig 3.B) showed a dose-increase response starting at $0.1 \mathrm{~Gy}$, peaking at $3 \mathrm{~Gy}(13.2 \%$ apoptotic cells), all irradiated samples showed significant difference from control $(p=0.000)$. At day 7 CBA showed very low levels of apoptosis, with significant elevation above control in the low dose range (0.01 and $0.1 \mathrm{~Gy}, \mathrm{p}=0.000)$, and also at $3 \mathrm{~Gy}$, 
but at minimal levels (below 2\% apoptotic cells). Whilst C57 showed perpetuation of significantly elevated apoptotic levels 7 days after exposure compared to control cells $(p=0.000)$, peaking in the 1 Gy group at $8.8 \%$ apoptotic cells. 


\section{Discussion}

It is becoming increasingly clear that non-targeted effects are not universally expressed following irradiation, which is the cause of much controversy in the field. This heterogeneity of response is likely due to a range of influencing factors (Salomaa et al. 2010)), including radiation type and dose, cell type, tissue type and genetic predisposition, amongst others. Whilst these factors have been studied separately the links between them are less understood. The focus of this study was to investigate the relationship between these factors, in particular genetic background and radiation dose in the context of signalling events. Simultaneously, temporal aspects were also evaluated to study whether initiation events (2-24h post-irradiation/0-1 PD) are linked to the outcome of delayed effects of radiation (genomic instability, here taken as 13-15 PD).

The results show clear strain specific differences for signalling and molecular endpoints, particularly with respect to levels of cytokines, TGF- $\beta$ and TNF- $\alpha$, and as such likely contribute to the respective radio-sensitivity and resistance shown by the two strains. Radiation responses independent of dose were also observed, in the case of calcium flux induction, media generated from both CBA and C57 stimulated responses in reporter cells, down to the lowest dose tested (0.01 Gy). Our results also showed that apoptosis levels differed between the strains with CBA apoptosis levels higher at 24h compared to $\mathrm{C} 57$, but $\mathrm{C} 57$ showed a higher level of apoptosis at the $7 \mathrm{~d}$ (delayed) time point. C57 showed a higher baseline level of apoptosis than CBA. Results here provide evidence for a significant influence of the genetic component in levels of apoptosis induction and type of cytokines.

Our study also explored the role of dose dependency in the above endpoints in these strains of mice. The results/discussion above showed TGF- $\beta$ (CBA) and TNF- $\alpha$ (C57) followed a dose-increase response at the delayed time point. A radiation dose increase response of levels of cytokines IL-12 and IL-18 has previously been reported (Shan et al. 2007). The two cytokines we have measured in this study both play significant roles in apoptotic induction, TGF- $\beta$ via the SMAD or death-associated protein 6 (DAXX) pathways and TNF- $\alpha$ via MAPK/JNK or caspase 8 activation. The elevated levels of TGF- $\beta$ in CBA at the delayed time point does not correlate with increased apoptosis, so it is possible that TGF- $\beta$ at the delayed time point is involved in pathways other than apoptosis induction e.g. cell cycle control (blocks G1 progression). It is possible that in CBA increased TGF- $\beta$ levels precede apoptosis, and our 
sampling time point for detecting apoptosis did not capture this rise. Levels of apoptosis were elevated in C57 at day 7, so this may correlate with TNF- $\alpha$ signalling.

TGF- $\beta 1$ is known to play a role in suppression of genomic instability/maintaining genome stability (Glick et al. 1996), and its absence in C57 demonstrated here, in combination with induction of delayed chromosomal instability, would suggest that in the in vitro model system TGF- $\beta$ has a role in long term signalling. Indeed, TGF- $\beta 1$ association in inter-cellular signalling has been described previously (Shao et al. 2008), where it was demonstrated that TGF- $\beta$ induced $\mathrm{Ca}^{2+}$ flux in reporter cells, which in turn led to generation of reactive nitrogen species. Our observation of $\mathrm{Ca}^{2+}$ flux induction by the ICCM of both CBA and C57, suggest that factors other than TGF- $\beta$ can induce flux, as C57 show very low levels of TGF- $\beta$. The effects resulting from a lack of TGF- $\beta$, and associated implications in DNA damage response and genomic instability, may also be exacerbated by increased levels of TNF- $\alpha$ which have been shown to be a potential soluble bystander signalling molecule, capable of inducing genomic instability in bystander cells via generation of ROS (Natarajan et al. 2007, Gibbons 2008). Evidence for TGF- $\beta$ involvement in bystander signalling has been demonstrated in other systems (high LET radiation, high dose) e.g. Han et al. 2010, Kruse et al. 2009, BurdakRothkamm et al. 2007).

Conversely, TNF- $\alpha$ is a pro-inflammatory cytokine, able to induce DNA damage (Fehsel et al. 1991), and is also involved in other signalling pathways. TNF- $\alpha$ has been implicated in bystander signalling, when anti-TNF- $\alpha$, (and dimethyl sulfoxide (DMSO)and 2-(4-Carboxyphenyl)-4,4,5,5tetramethylimidazoline-1-oxyl-3-oxide (c-PTIO)) were added to media from 4 Gy gamma whole body irradiated CBA and C57 incubated for $1 \mathrm{~h}$ and placed onto fresh cells, a decrease in the chromosomal damage manifested in bystander cells was observed (Lorimore et al. 2008), with no cross-signalling between C57 and CBA. In vivo production of TNF- $\alpha$ (and other cytokines) by peritoneal macrophages and splenocytes after whole body irradiation of BALB/c mice with single low doses of 0.1 or 0.2 Gy Xray has previously been shown (Cheda et al. 2008). Release of anti-tumour cytokines including TNF- $\alpha$, IL-1B and IL-12 from peritoneal macrophages, for TNF- $\alpha$ levels begin to elevate on day 1, significantly different from day 2-9 (end of experimental period), thus demonstrating that low dose X-ray exposure can lead to detectable signalling changes in vivo. 
The link between genetics and dose response in apoptosis is less clear cut. With CBA apoptosis levels showing no dose response increase, whereas C57 levels rose with dose (up to $3 \mathrm{~Gy}$ at early time point and up to 1 Gy at the delayed time point). Recent work by Zyuzikov et al. (2011) showed that at an immediate/very early time (3h) post-radiation strain and dose specific responses were apparent following in vivo exposure, they demonstrated a strain specific apoptotic response, with C57 having a threshold of 0.05 Gy and 0.1 Gy for CBA in induction of p53/p21 dependent apoptosis. With respect to Caspase-3 induction for both strains no increase in activity was seen below $0.1 \mathrm{~Gy}(0.2 \mathrm{~Gy}$ triggered response in both strains), and 0.5 Gy for terminal deoxynucleotidyl transferase dUTP nick end labeling (TUNEL) assay (Zyuzikov et al. 2011) indicating that choice of biological response measurement is a crucial element of investigation/interpretation of data. The annexin $\mathrm{V}$ assay used in this study measures phosphatidylserine (PS) on the outer surface of the plasma membrane, which is an early marker of apoptosis, PS transfers from inner to outer face of the plasma membrane soon after apoptosis induction (Koopman et al. 1994). Our Annexin $V$ apoptosis induction data shows no apparent effect at the immediate $(2 \mathrm{~h})$ time point, but a dose increase response for $\mathrm{C} 57$, beginning at $0.1 \mathrm{~Gy}$, whilst CBA shows a biphasic dose response (with peaks at 0.01 and $1 \mathrm{~Gy}$ ) at 24h. Interestingly, in a parallel study to the work presented here, C57 showed more complex chromosomal damage than CBA at delayed time points (data not shown) following low LET irradiation suggesting that the timing/triggering of apoptotic clearance has an impact on later manifestations of instability.

Radiation-induced apoptosis is a key radiation response, removing cells with irreparable levels of damage which would otherwise be unstable or unviable. Our data showed a genetic trend in apoptosis levels. The difference in apoptosis may be due to inherent differences in radiation sensitivity of the respective strain cells, or could be influenced by the mix/type of cells present in the liquid culture and differing strain specific traits therein. Coates et al. (2008b) demonstrated that in vivo CBA and C57 have differing macrophage types, CBA having pro-inflammatory M1-like, and C57 M2-like (anti-inflammatory). Post 4 Gy gamma in vivo exposure C57 show decreased nitric oxide synthase 2 activity and increased arginase activity indicative of increased M2 response, whilst CBA showed no changes, consistent with M1 macrophage response. In vitro alterations were not detected. As macrophage activation is associated with phagocytic clearance of apoptosing cells - it is proposed that the different strains use different pathways/activation for cell clearance. The lack of in vitro response in Coates et al. was ascribed to the fact that radiation responses are at the tissue level. 
However the data presented here is in contrast to this - showing differential cytokine levels in vitro and ergo, changes in protein expression - and further on impacts on a number of different signalling pathways with different potential biological results.

These results highlight the necessity to sample at more than one time point to obtain an indication of the temporal dynamics of apoptosis induction, or indeed any other response. These results suggest that sampling time is time is critical when evaluating non-targeted effects, especially in the case of low LET radiation which has biphasic cellular response/effects (Ghandhi et al. 2010) thus measuring responses at only one time point can potentially lead to 'missing' cellular responses.

Induction of apoptosis following irradiation leads to the removal of damaged cells and thus reduces the likelihood of transmission of genetic damage to cell progeny. As such strains which have a greater tendency to undergo apoptosis will show less long term genomic instability as a greater proportion of the cells that will initiate/propagate the GI will survive. In contrast, strains with a propensity for lower apoptosis will retain more cells and thus the perpetuation of $\mathrm{Gl}$ in later generations will be higher. This has been previously demonstrated with CBA and C57 mice strains, where CBA show lower rates of apoptosis and higher rates of GI and are thus termed 'radio-sensitive' whilst C57 has a higher apoptotic rate, lower GI and are thus 'radio-resistant' (Watson et al. 1997). Media from irradiated C57 samples has been shown to initiate calcium flux in HPV-G reporter cells (Mothersill et al. 2006, Singh et al. 2011), whilst CBA irradiated and control media showed no effect on calcium flux in this system. This suggests that irradiated C57 cells produce signalling molecules which affect neighbouring cells, potentially enhancing the apoptosis rate in non-irradiated bystander populations. Results presented here are in partial agreement with this data, as C57 ICCM initiated a calcium flux in the L929 reporter cells, but in addition CBA also initiated calcium flux in the reporter cell line. The L929 cells were chosen for this experimental design in order to keep species continuity within the experiment, with the rationale that data would be better extrapolated to the in vivo state than in a situation where human reporter cells are used with mouse derived media samples. As stated above, calcium flux induction was observed in $\mathrm{L929}$ reporter cells exposed to ICCM from all radiation doses, but not in the corresponding control groups. Such global induction of calcium fluxes on incubation with ICCM is in agreement with similar observations in human cell lines (Lyng et al. 2011). Lyng et al. (2011) used the same ICCM incubation approach with $\mathrm{HaCaT}$ (human keratinocytes) irradiated at 0.005, 0.05 and 0.5 
Gy (well within the low dose range). They went further and demonstrated by inhibition of ROS, NO and extracellular calcium, that ROS and calcium were involved in bystander signalling and response, whilst NO was involved in bystander response only. They also demonstrated lipid-raft mediated signalling leads to calcium flux in bystander cells treatment with filipin (a membrane signalling/lipid raft inhibitor) abolished changes in membrane permeability and calcium flux. TNF- $\alpha$, TGF- $\beta$, IL-33 and insulin-like growth factor 1 (IGF-1) all signal via lipid rafts and have been implicated in bystander signalling (reviewed by Hamada et al. 2011). Yamazaki et al. (2006) demonstrated cytokine signalling via lipid rafts in haemopoietic niche cells and this could be applicable to the murine model used in this work. The lack of low dose cut-off for calcium flux induction highlights that bystander signalling is occurring at very low doses, and whilst this may not correlate with significant damage induction in the short to medium term, one cannot discount the possibility of more subtle cumulative effects contributing to the overall damage burden of an organism.

In conclusion, this work has shown that genetic background plays a significant role in the signalling mechanisms underlying induction and perpetuation of genomic instability following radiation exposure. All groups were capable of inducing calcium flux, and as such indicates signalling induction including at very low irradiation doses. Higher apoptosis levels were observed for CBA than C57, CBA preferentially used TGF $\beta$ and C57 TNF $\alpha$ responses. This highlights a link between initial signalling events and longer term effects, which warrants deeper investigation to identify possible points for exploitation e.g. in targeting therapy/ameliorating abscopal effects. 


\section{Acknowledgements}

The authors wish to thank David Stephens for performing irradiations and Stuart Townsend for FACS expertise. We also gratefully acknowledge David Papworth for guidance in sample size calculations. 


\section{Declaration of Interest statement}

The authors report no conflicts of interest. This work was supported by the NOTE IP 036465 (FI6R), Euratom specific programme for research and training on nuclear energy, 6th FP of the EC. 


\section{References}

Averbeck D. 2010. Non-targeted effects as a paradigm breaking evidence. Mutation Research 687: 712.

Burdak-Rothkamm S, Short SC, Folkard M, Rothkamm K, Prise KM. 2007. ATR-dependent radiationinduced gamma $\mathrm{H} 2 \mathrm{AX}$ foci in bystander primary human astrocytes and glioma cells. Oncogene. 26: 993-1002.

Burr KL, Robinson JI, Rastogi S, Boylan MT, Coates PJ, Lorimore SA, Wright EG. 2010. Radiationinduced delayed bystander-type effects mediated by hemopoietic cells. Radiation Research 173: 760-768.

Cheda A, Nowosielska EM, Wrembel-Wargocka J, Janiak MK. 2008. Production of cytokines by peritoneal macrophages and splenocytes after exposures of mice to low doses of X-rays. Radiation andEnvironmental Biophysics 47: 275-283.

Coates PJ, Robinson JI, Lorimore SA, Wright EG. 2008a. Ongoing activation of p53 pathway responses is a long-term consequence of radiation exposure in vivo and associates with altered macrophage activities. Journal of Pathology 214: 610-616.

Coates PJ, Rundle JK, Lorimore SA, Wright EG. 2008b. Indirect macrophage responses to ionizing radiation: implications for genotype-dependent bystander signaling. Cancer Research 68: 450456.

Dieriks B, De Vos WH, Derradji H, Baatout S, Van Oostveldt P. 2010. Medium-mediated DNA repair response after ionizing radiation is correlated with the increase of specific cytokines in human fibroblasts. Mutation Research 687:40-48.

Esposito G, Belli M, Campa A, Cherubini R, Cuttone G, Dini V, Furusawa Y, Gerardi S, Simone G. 2006. DNA fragments induction in human fibroblasts by radiations of different qualities. Radiation Protection Dosimetry 122:166-168.

Facoetti A, Ballarini F, Cherubini R, Gerardi S, Nano R, Ottolenghi A, Prise KM, Trott KR, Zilio C. 2006. Gamma ray-induced bystander effect in tumour glioblastoma cells: a specific study on cell survival, cytokine release and cytokine receptors. Radiation Protection Dosimetry 122: 271274.

Fehsel K, Kolb-Bachofen V, Kolb H. 1991. Analysis of TNF alpha-induced DNA strand breaks at the single cell level. American Journal of Pathology 139): 251-254.

Ghandhi SA, Ming L, Ivanov VN, Hei TK, Amundson SA. 2010. Regulation of early signaling and gene expression in the alpha-particle and bystander response of IMR-90 human fibroblasts. BMC Medical Genomics 3: 31.

Gibbons C. 2008. Genomic instability induced by low-dose ionizing radiation and tumor necrosis factor-alpha. PhD thesis. University of California, Riverside. 214 p.

Glick AB, Weinberg WC, Wu IH, Quan W, Yuspa SH. 1996. Transforming growth factor beta 1 suppresses genomic instability independent of a G1 arrest, p53, and Rb. Cancer Research 56: 3645-3650.

Gridley DS, Pecaut MJ, Green LM, Sanchez MC, Kadhim MA. 2011. Strain-related differences and radiation quality effects on mouse leukocytes: gamma-rays and protons (with and without aluminum shielding). In Vivo. 25: 871-880.

Hamada N, Maeda M, Otsuka K, Tomita M. 2011. Signaling pathways underpinning the manifestations of ionizing radiation-induced bystander effects. Current Molecular Pharmacology 4: 79-95.

Han W, Chen S, Yu KN, Wu L. 2010. Nitric oxide mediated DNA double strand breaks induced in proliferating bystander cells after alpha-particle irradiation. Mutation Research 684: 81-89. 
Ivanov VN, Zhou H, Ghandhi SA, Karasic TB, Yaghoubian B, Amundson SA, Hei TK. 2010. Radiationinduced bystander signaling pathways in human fibroblasts: A role for interleukin-33 in the signal transmission. Cellular signalling 22: 1076-1087.

Kadhim MA, Macdonald DA, Goodhead DT, Lorimore SA, Marsden SJ, Wright EG. 1992. Transmission of chromosomal instability after plutonium alpha-particle irradiation. Nature 355: 738740.Kadhim MA, Lorimore SA, Hepburn MD, Goodhead DT, Buckle VJ, Wright EG. 1994. Alphaparticle-induced chromosomal instability in human bone marrow cells. Lancet 344: 987-988.

Kadhim MA, Hill MA, Moore SR. 2006. Genomic instability and the role of radiation quality. Radiation Protection Dosimetry 122: 221-227.

Koopman G, Reutelingsperger CP, Kuijten GA, Keehnen RM, Pals ST, van Oers MH. 1994. Annexin V for flow cytometric detection of phosphatidylserine expression on B cells undergoing apoptosis. Blood. 84: 1415-1420.

Kruse JJ, Floot BG, te Poele JA, Russell NS, Stewart FA. 2009. Radiation-induced activation of TGF-beta signaling pathways in relation to vascular damage in mouse kidneys. Radiation Research 171: 188-197.

Liu Z. 2005. Molecular mechanism of TNF signalling and beyond. Cell Research 15: 24-27.

Lorimore SA, Chrystal JA, Robinson JI, Coates PJ, Wright EG. 2008. Chromosomal instability in unirradiated hemaopoietic cells induced by macrophages exposed in vivo to ionizing radiation. Cancer Research 68: 8122-8126.

Lyng FM, Seymour CB, Mothersill C. 2002. Early events in the apoptotic cascade initiated in cells treated with medium from the progeny of irradiated cells. Radiation Protection Dosimetry 99: 169-172.

Lyng FM, Maguire P, McClean B, Seymour C, Mothersill C. 2006. The involvement of calcium and MAP kinase signaling pathways in the production of radiation-induced bystander effects. Radiation Research 165: 400-409.

Lyng FM, Howe OL, McClean B. 2011. Reactive oxygen species-induced release of signalling factors in irradiated cells triggers membrane signalling and calcium influx in bystander cells. International Journal of Radiation Biology 87: 683-695.

Maguire P, Mothersill C, Seymour C, Lyng FM. 2005. Medium from irradiated cells induces dosedependent mitochondrial changes and BCL2 responses in unirradiated human keratinocytes. Radiation Research 163: 384-390.

Morgan WF. 2003. Non-targeted and delayed effects of exposure to ionizing radiation: I. Radiationinduced genomic instability and bystander effects in vitro. Radiation Research. 159: 567-580.

Morgan WF. 2003. Non-targeted and delayed effects of exposure to ionizing radiation: II. Radiationinduced genomic instability and bystander effects in vivo, clastogenic factors and transgenerational effects. Radiation Research 159: 581-596.

Mothersill C, Lyng F, Seymour C, Maguire P, Lorimore S, Wright E., 2005. Genetic factors influencing bystander signaling in murine bladder epithelium after low-dose irradiation in vivo. Radiation Research 163: 391-399.

Mothersill C, Seymour RJ, Seymour CB. 2006. Increased radio-sensitivity in cells of two human cell lines treated with bystander medium from irradiated repair-deficient cells. Radiation Research 165: 26-34.

Nagasawa H, Little JB. 1999. Unexpected sensitivity to the induction of mutations by very low doses of alpha-particle radiation: evidence for a bystander effect. Radiation Research 152: 552-557. 
Natarajan M, Gibbons CF, Mohan S, Moore S, Kadhim MA. 2007. Oxidative stress signalling: a potential mediator of tumour necrosis factor alpha-induced genomic instability in primary vascular endothelial cells. British Journal of Radiology. 80 Spec No 1:S13-22.

Orrenius S, Zhivotovsky B, Nicotera P. 2003. Regulation of cell death: the calcium-apoptosis link. Nature Reviews Molecular and Cell Biology 4: 552-565.

Ponnaiya B, Cornforth MN, Ullrich RL. 1997. Radiation-induced chromosomal instability in BALB/c and C57BL/6 mice: the difference is as clear as black and white. Radiation Research 147: 121-125.

Salomaa S, Wright E, Hildebrandt G, Kadhim M, Little M, Prise K, Belyakov, OV (2010). Editorial. Mutation Research 687: 1-2

Shan YX, Jin SZ, Liu XD, Liu Y, Liu SZ. 2007. Ionizing radiation stimulates secretion of pro-inflammatory cytokines: dose-response relationship, mechanisms and implications. Radiation and Environmental Biophysics. 46: 21-29.

Shao C, Lyng FM, Folkard M, Prise KM. 2006. Calcium fluxes modulate the radiation-induced bystander responses in targeted glioma and fibroblast cells. Radiation Research 166: 479-487.

Shao C, Folkard M, Prise KM. 2008. Role of TGF-beta1 and nitric oxide in the bystander response of irradiated glioma cells. Oncogene 27: 434-440.

Shen HM, Lin Y, Choksi S, Tran J, Jin T, Chang L, Karin M, Zhang J, Liu ZG. 2004. Essential roles of receptor interacting protein and TRAF2 in oxidative stress-induced cell death. Molecular and Cellular Biology 24: 5914-5922.

Shi Y, Massagué J. 2003. Mechanisms of TGF- $\beta$ signalling from cell membrane to the nucleus. Cell 113: 685-700.

Singh H, Saroya R, Smith R, Mantha R, Guindon L, Mitchel RE, Seymour C, Mothersill C. 2011. Radiation induced bystander effects in mice given low doses of radiation in vivo. Dose Response 9: 225-242.

Takahashi M, Takakura K, Furusawa Y. 2010. Comparison of the kinetics of radiation-induced apoptosis in DT40 cells irradiated with low and high doses of $\mathrm{X}$ rays. Radiation Research 173:645-650.

Watson GE, Lorimore SA, Clutton SM, Kadhim MA, Wright EG. 1997. Genetic factors influencing alphaparticle-induced chromosomal instability. International Journal of Radiation Biology 71: 497503.

Watson GE, Pocock DA, Papworth D, Lorimore SA, Wright EG. 2001. In vivo chromosomal instability and transmissible aberrations in the progeny of haemopoietic stem cells induced by high- and low-LET radiations. International Journal of Radiation Biology 77: 409-417.

Yamazaki S, Iwama A, Takayanagi S, Morita Y, Eto K, Ema H, Nakauchi H. 2006. Cytokine signals modulated via lipid rafts mimic niche signals and induce hibernation in hematopoietic stem cells. EMBO Journal 25: 3515-3523.

Zyuzikov NA, Coates PJ, Parry JM, Lorimore SA, Wright EG. 2011. Lack of nontargeted effects in murine bone marrow after low-dose in vivo $X$ irradiation. Radiation Research 175: 322-327. 


\section{Tables and Figures}

\section{Figure legends}

Figure 1. Total levels of cytokines (pg/cell) of TGF $\beta$ and TNF $\alpha$ in CBA and C57 at $2 \mathrm{~h}, 24 \mathrm{~h}$ and $7 \mathrm{~d}$ post Xirradiation (0-3 Gy). Error bars \pm SEM. A: Levels of TGF $\beta /$ cell in CBA, B: Levels of TNF $\alpha /$ cell in CBA, C: Levels of TGF $\beta$ /cell in C57, D: Levels of TNF $\alpha /$ cell in C57.

Figure 2. Calcium flux in murine fibroblast reporter cells (L929) on addition of irradiated cell conditioned medium. A: CBA ICCM $2 \mathrm{~h}$ post irradiation, B: C57 ICCM 2h post-irradiation, C: CBA ICCM $24 \mathrm{~h}$ post irradiation, D: C57 ICCM 24h post irradiation, E: CBA ICCM 7d post-irradiation, F: C57 ICCM 7d post irradiation. Media from both CBA and C57 samples induced calcium flux in most instances. Controls showed no flux induction. G: Calcium levels following addition of $2 \mathrm{~h}, 24 \mathrm{~h}$ and $7 \mathrm{~d}$ sham irradiated CBA ICCM. $\mathrm{H}$ : Calcium levels following addition of $2 \mathrm{~h}, 24 \mathrm{~h}$ and 7d sham irradiated C57 ICCM.

Figure 3. Levels of apoptotic cells in CBA and C57 haemopoietic cells $2 \mathrm{~h}, 24 \mathrm{~h}$ and $7 \mathrm{~d}$ after exposure to a range of X-ray doses (0 - $3 \mathrm{~Gy}$ ). A) Percentage of apoptotic cells in liquid cultured CBA bone marrow cells. B) Percentage of apoptotic cells in liquid cultured C57 bone marrow cells. 
A

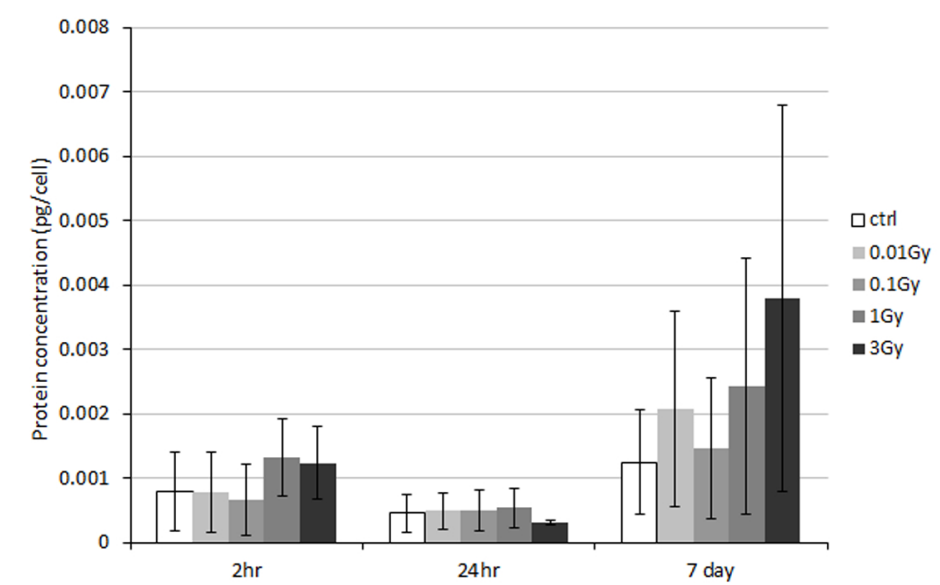

C

C57 TGF $\beta$

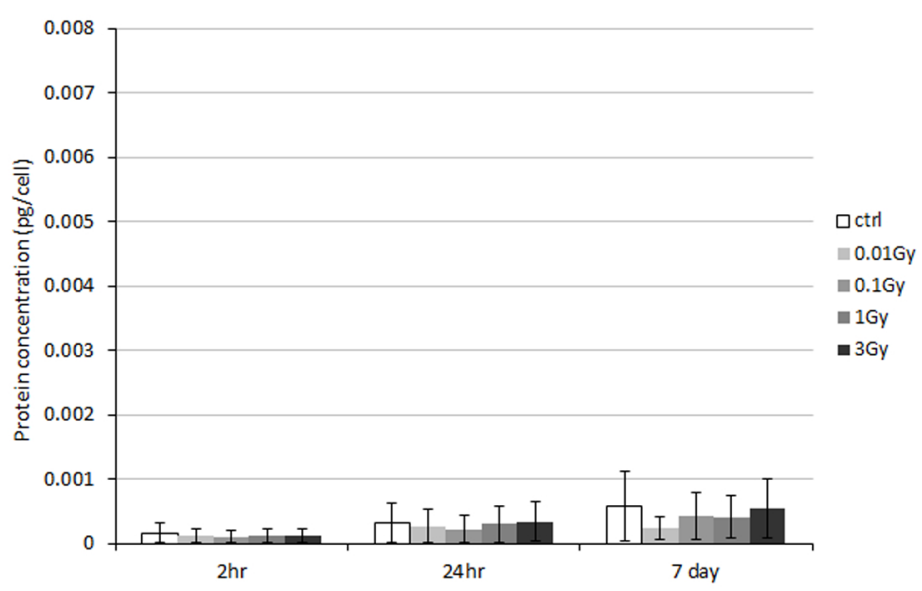

B

CBA TNF $\alpha$

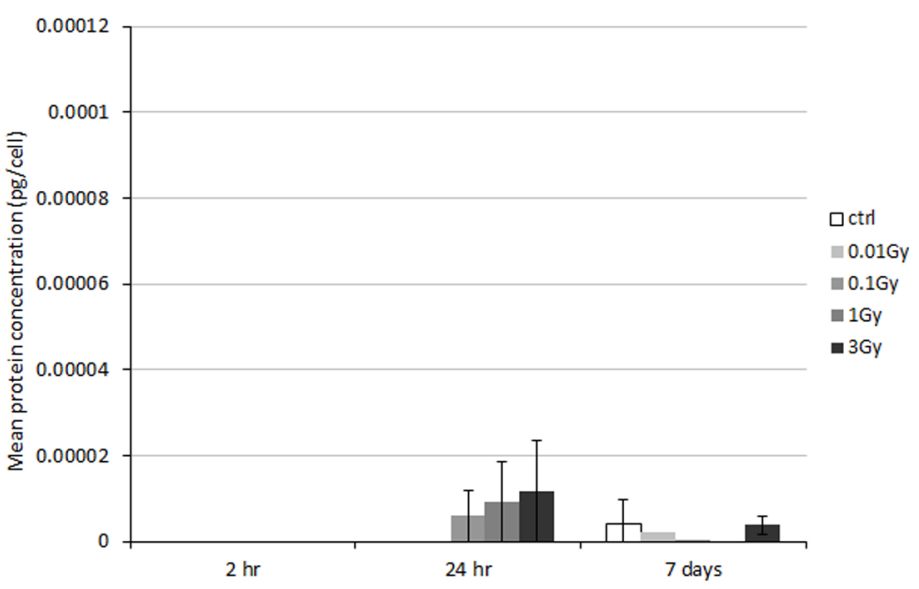

D

C57 TNF $\alpha$

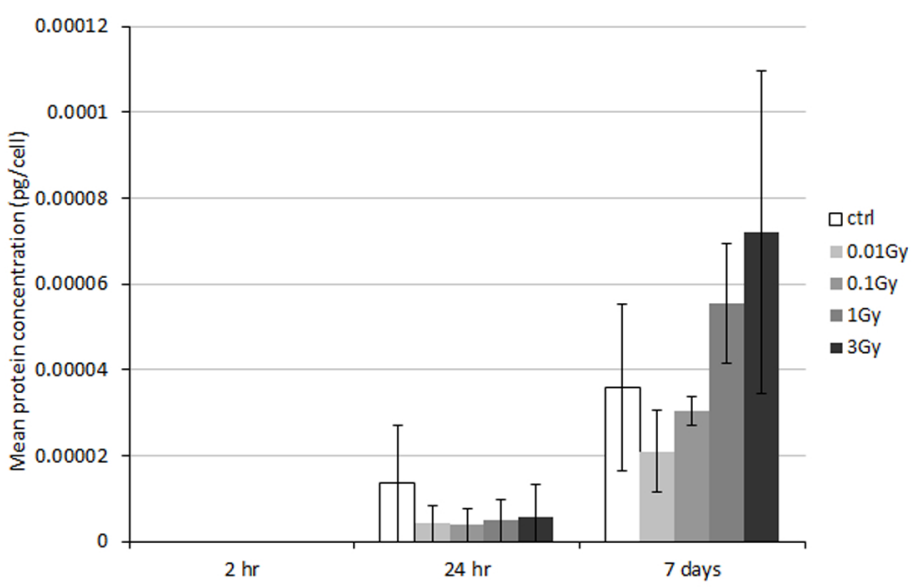

Figure 1. Total levels of cytokines (pg/cell) of TGF $\beta$ and TNF $\alpha$ in CBA and C57 at $2 \mathrm{~h}, 24 \mathrm{~h}$ and $7 \mathrm{~d}$ post $X$-irradiation (0-3Gy). Error bars \pm SEM. A: Levels of TGF $\beta /$ cell in CBA, B: Levels of TNF $\alpha /$ cell in CBA, C: Levels of TGF $\beta /$ cell in C57, D: Levels of TNF $\alpha /$ cell in C57. 

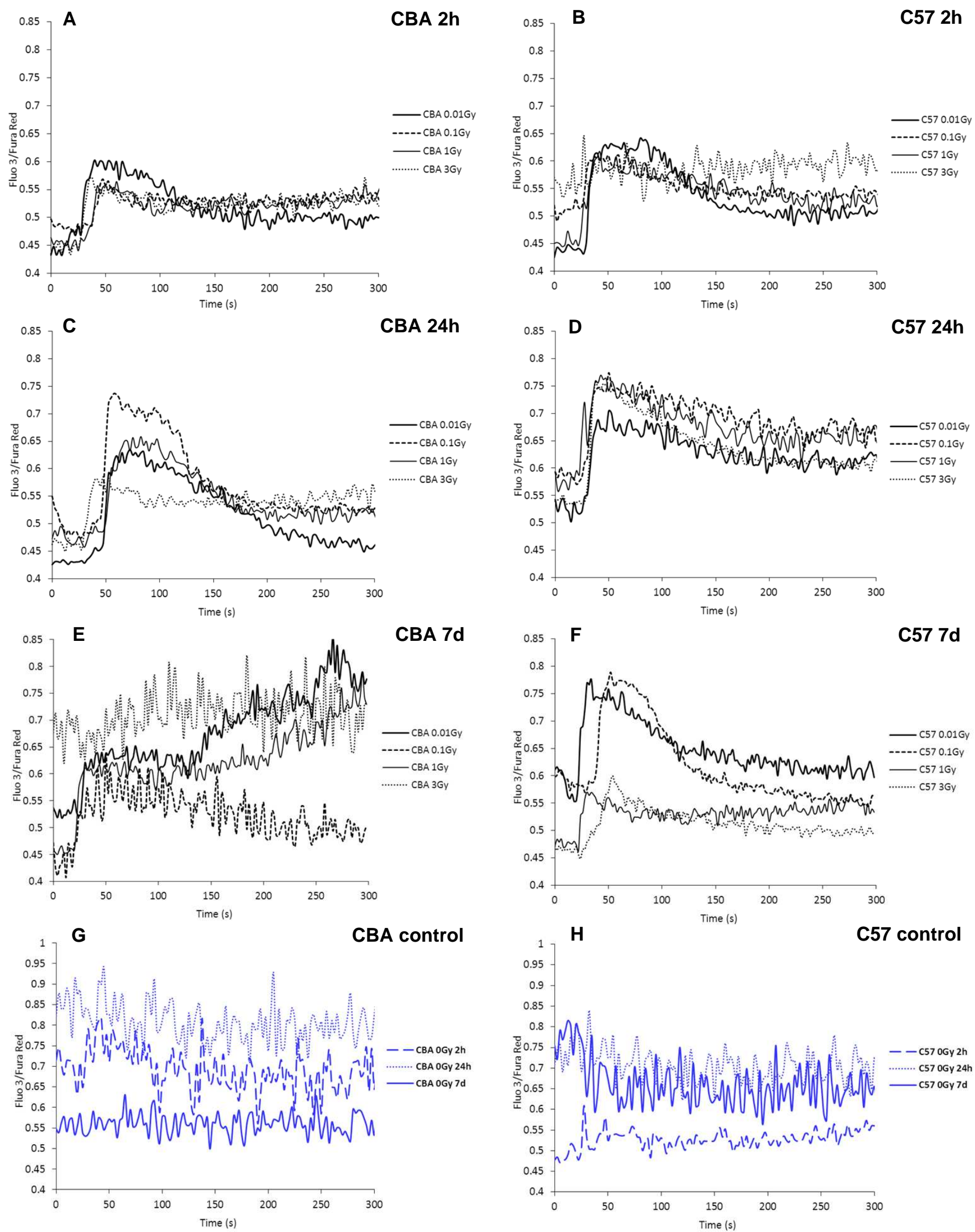

Figure 2. Calcium flux in murine reporter cells (L929) on addition of irradiated cell conditioned medium. A: CBA ICCM 2h post-irradiation, B: C57 ICCM 2h post irradiation, C: CBA ICCM 24h post irradiation, D: C57 ICCM 24h post irradiation, E: CBA ICCM 7d post irradiation, F: C57 ICCM 7d post irradiation. Media from both CBA and C57 samples induced calcium flux in most instances. Controls G: CBA and H: C57 both showed no flux induction. 
A. CBA

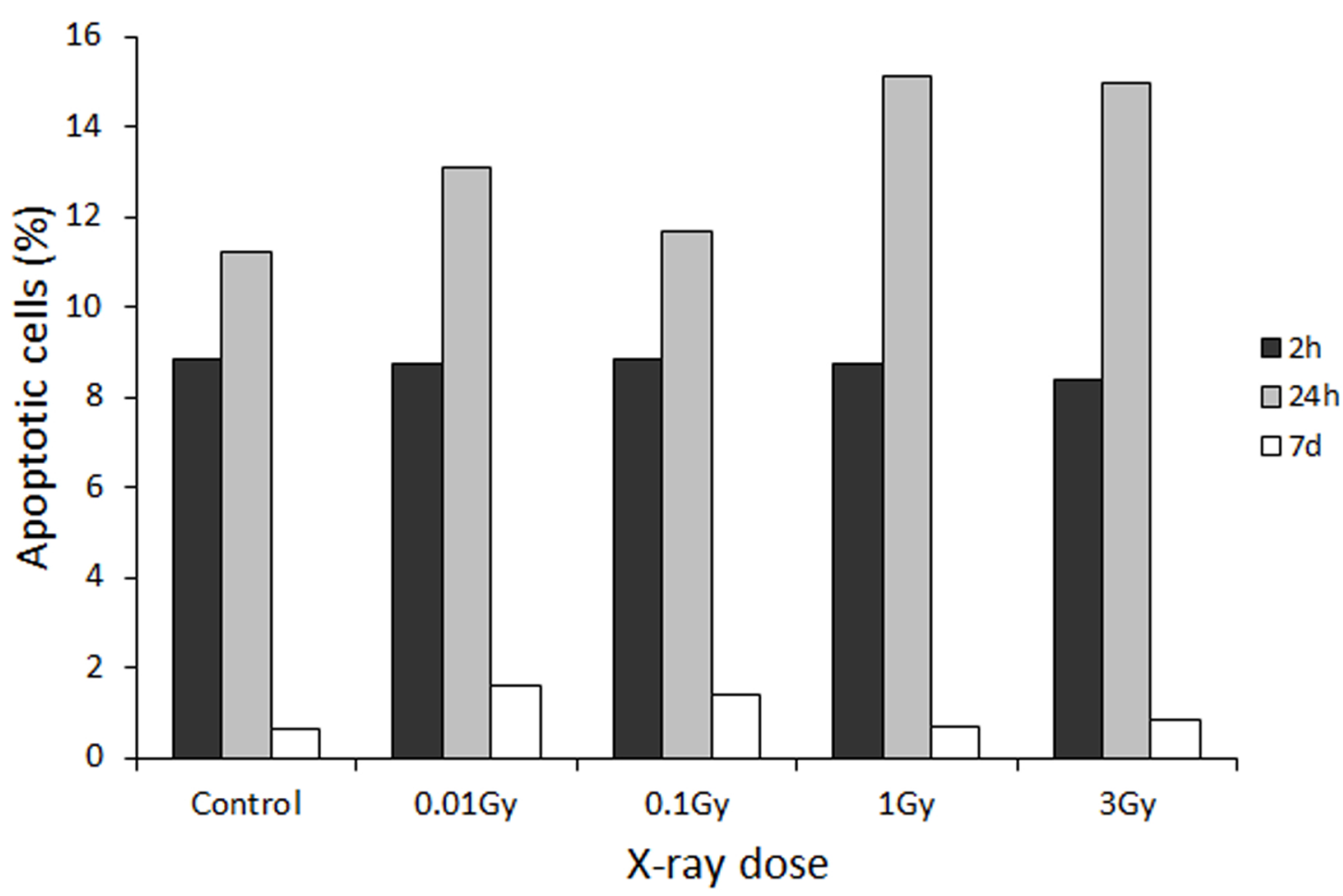

B. $\mathrm{C} 57$

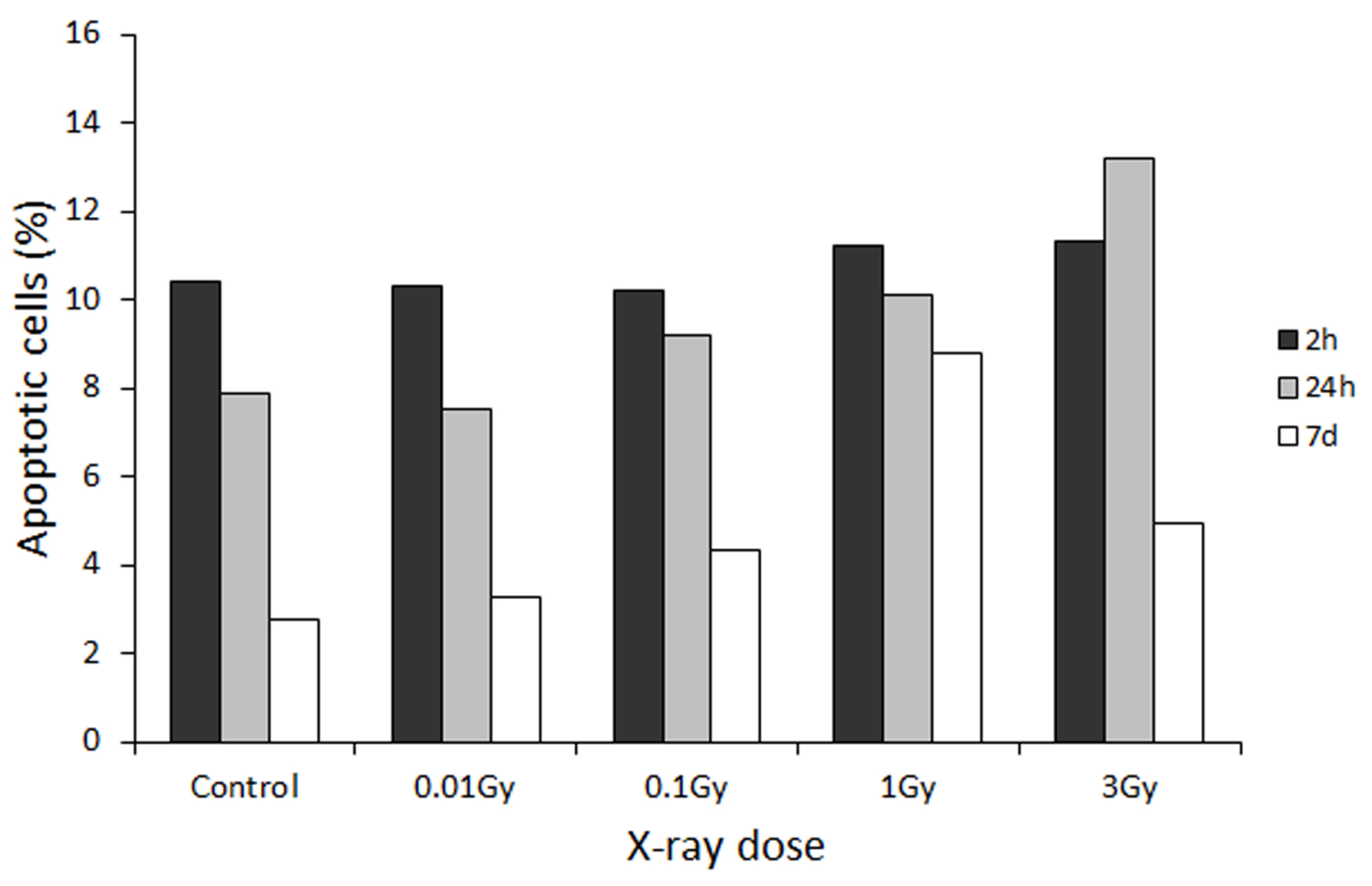

Figure 3. Levels of apoptosis in CBA and C57 haemopoietic cells $2 \mathrm{~h}, 24 \mathrm{~h}$ and $7 \mathrm{~d}$ after exposure to a range of $X$-ray doses (0-3Gy). A: Percentage of apoptotic cells in liquid cultured CBA cells, B: Percentage of apoptotic cells in liquid cultured C57 cells. 